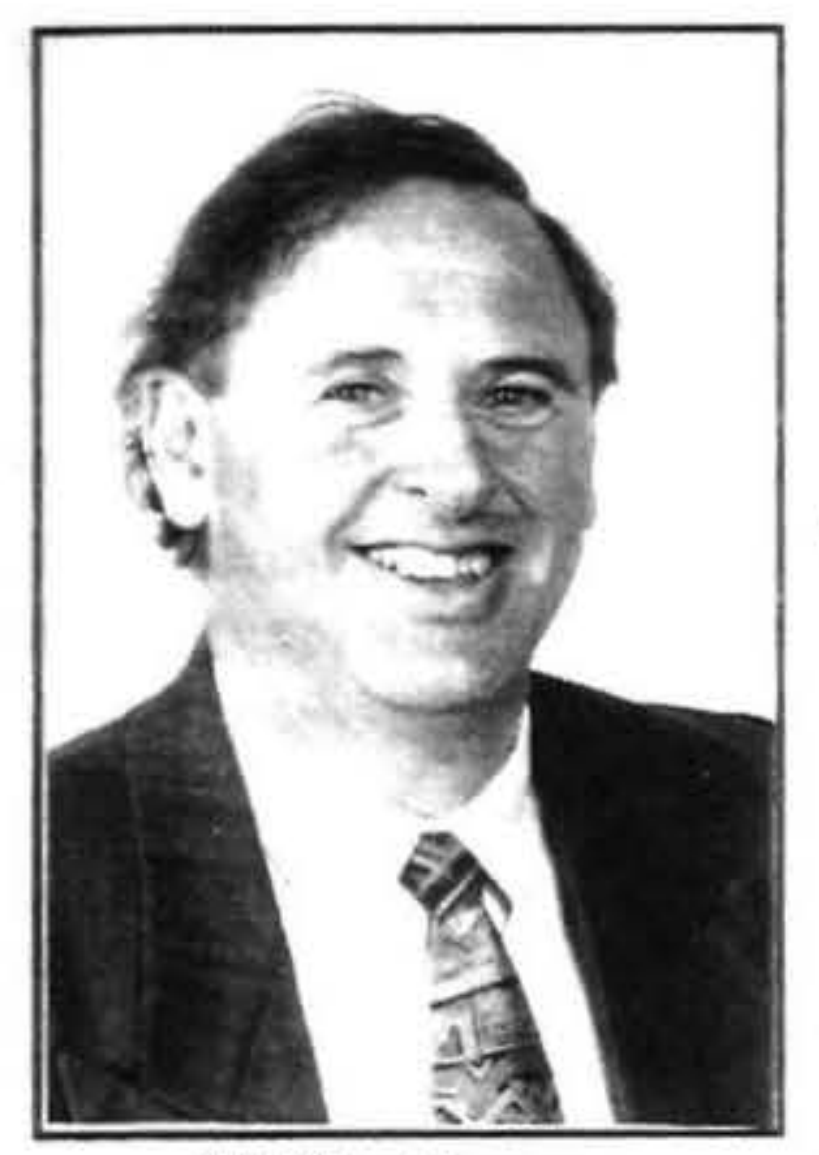

Phillip Capper

\title{
NEW ZEALAND RESEARCH ON SKILLS FORMATION AND THE 'LEARNING ORGANISATION': CRITICAL ANALYSIS OF THE CASE STUDY METHODOLOGY
}

\author{
ERSF PROJECT TEAM \\ Tony Bullard, Phillip Capper (Presenter), Kathryn Hawes, \\ Roberta Hill, Evelyn Richardson, Ward Weldon (Adviser).
}

New Zealand Institute for Social Research \& Development

\section{Abstract}

In recent years there has been continuing debate about what skills are needed for New Zealand's competitive business environment. Many commentators talk of a skills crisis, while some academics argue that the skills crisis is a myth. Recent research on workplace reform in seven 'leading edge' New Zealand companies highlights six crucial limitations of the debate. These are a focus on: $i$ ) individual skills rather than organisational culture, work design and employment relationships; ii) formal training rather than work-based learning; iii) the skills of school leavers rather than those of managers, supervisors and workers; and iv) technical, rather than organisational and team, skills. The debate also pays inadequate attention to $v)$ how people learn in teams; and vi) the complexity of the current business and policy environment. In November 1993, NZISR \&D commenced a FRST-funded, three-year project on 'Economic Restructuring and Skills Formation' to address these limitations. Based on five case studies in a range of sectors, the project examines characteristics of enterprises seeking sustainable competitive advantage by operating as a 'learning organisation'; one where the organisational structure itself is an environment for continuing education. Case study analysis is also used to understand the relationship between the company's corporate strategy and skilling process; the core skills required by managers, supervisors and workers, and how these are formed. The purpose of this paper is to outline the project's case study design, explain why this methodology has been selected and examine debates about its validity and utility.

Increased exposure of New Zealand to international competition following deregulation in the 1980 s has put existing businesses under strain. Manufacturers traditionally operating in protected and regulated markets are seeking new ways of increasing their competitiveness, and, like service sector organisations, are seeking to improve the quality of the products and services they provide to their customers (Davidson, Hill and Perry, in press). Reflecting these economic changes, the New Zealand education and training environment is also undergoing significant change. In these respects New Zealand organisations are facing similar challenges to their contemporaries throughout the world.

This paper outlines the methodological framework for a three-year research project on 'Economic Restructuring and Skills Formation' (ERSF) in New Zealand enterprises in this complex, rapidly changing business and policy environment. The project commenced in November 1993 and is funded by a major grant from the New Zealand Foundation for Research, Science \& Technology. The paper's purpose is to: (i) outline the background and rationale for the project; (ii) outline the project's design and explain how and why the methodology has been selected, and (iii) examine debates about the validity and generalisability of this type of research.

\section{Skill formation and workplace reform}

Research on workplace reform by the New Zealand Institute for Social Research \& Development Limited (Davidson, Hill and Perry, in press) provided the impetus for the ERSF project in the context of the debate about what skills New Zealand needs to be internationally competitive and whether it is producing the right mix. The research provides an understanding of how an increasing number of New Zealand enterprises are responding to the internationalisation of the economy by introducing a range of Japanese and American production systems and work practices. These include various adaptations of Total Quality Management (TQM) systems, Just-in-Time (JT) production methods, flattened organisational and management structures and the reorganisation of work into teams. Progressive companies are also pursuing competitive strategies that rely on a variety of forms of partnerships with customers, suppliers and employees.

United States and New Zealand business experience suggests, however, that the 'rate at which organisations learn may become the only sustainable competitive advantage' (de Geus, 1988). A 'learning organisation' is one skilled at creating, acquiring, and transferring knowledge, and at modifying its behaviour to reflect new knowledge and insights (Garvin, 1993). Commentators argue, therefore, 
that a critical issue for the enterprise is to create an organisational structure and culture that facilitates continuous learning; one where 'the organizational structure itself is an environment for continuing education' (Emery, 1993). The case study analysis of seven 'leading edge' New Zealand companies suggests that this is most likely to occur with a team-based organisational structure(Davidson, Hill and Perry, in press).

Team-based working, particularly self-managing teams, is advocated widely as a key component of progressive workplace organisation. Increasingly differentiated product markets, shortening order periods and international competition, have put existing production systems under strain. In production environments, where design and quality are of greater importance than price and standardisation, team working is seen to enhance continuous innovation and responsiveness to customer demands. It is a feature of the 'flexible specialisation' route to work organisation which stresses the importance of a multi-skilled workforce, training, investment in new technology and a commitment to quality. Team working is thus consistent with the current stage of economic restructuring in New Zealand and is rapidly gaining acceptance in the context of the general increase in workplace reform initiatives in this country (Davidson, Hill and Perry, in press).

These different forms of economic restructuring have profound implications for skill formation processes and outcomes. For example, the move to team-based work and the emerging demand for multiskilling puts pressure on traditional skill acquisition and recognition systems and creates new demands such as skilling for devolution of responsibility and for the redesigning of organisational and socio-technical systems (Ford, 1991).

Successful skill formation is being seen by enterprises both in New Zealand and internationally as the most important indicator of a country's future prosperity (for example, see Smith, 1994.) Ford (1991) defines skill formation as:

an emerging holistic concept that embraces and integrates formal education, pre-employment activities, induction, on-the-job and off-the-job learning, equity and personal development and career options and opportunities.

[It is] an integrative concept of life-long learning which supports the interlacing of theory and practice, of education and experience, of formal and informal learning, of initial and recurrent learning, of on-the-job and off-thejob learning, of individual and team learning, and of team and enterprise learning.

However, as an OECD study on conceptual changes and innovations in skill formation at the enterprise level concluded, skill formation is a dramatic conceptual shift that exposes the lack of knowledge among the scholarly educational research community, and this requires 'significant innovative, action-oriented research' (Ford, 1991). The ERSF Project is one response to this challenge.

\section{The skills debate in New Zealand}

In recent years there has been continuous debate about what skills are needed for our competitive business environment and whether the country is producing the right level and mix. Many commentators talk of a skills crisis (for example, see Barnett, 1994), while some academics argue that the skills crisis is a myth (Snook, 1994; Gordon and Snook, 1992). Regardless of the merits of the various arguments, the workplace reform research and the concept of skill formation highlight five crucial limitations. The skills debate:

1. Focuses on the skill attributes of individuals at the expense of considering how workplaces might be structured and managed for ongoing skill formation in the present and future business environment. In other words, the debate tells us little about the relationship between skill formation and the organisational culture, structure, operating systems and production processes that characterise leading edge organisations competing in a global economy.

2. Concentrates on formal, school or tertiary-based education and training, at the expense of considering everyday work-based learning needed to create enterprises that are customer-focused, flexible, innovative and costefficient. As a consequence, it ignores the issue of how work should be designed to optimise the continuous improvement, or learning, that is central to TQM and JT production and customer service systems.

3. Addresses the skill levels of school leavers, or those out of work, at the expense of considering the knowledge, values and skills that managers, supervisors and staff require to create workplaces that facilitate continuous leaming.

4.Focuses on the acquisition of technical skills by an individual, rather than considering the organisational and team skills needed for the self-managing production and cross-functional teams that characterise leading edge companies.

5. Has not yet begun to grapple with the implications of the 'learning organisation' concept. In particular, inadequate attention is paid both to i) how people learn in the workplace, especially in a team and; ii) how the design of organisational structures might facilitate learning and appropriate skill formation if it is informed by understandings of how leaming occurs.

The Economic Restructuring and Skills Formation project has been designed to address these major inadequacies. 
A research report, including a literature review and scoping visit to United States' corporations and academic research centres (Capper et al, 1994), has helped to focus the planning of the ERSF Project. While this report provides a sound basis for further theory development through indepth New Zealand case study research, it also raises the question of whether some aspects of the research, and its preliminary findings, may be so firmly rooted in the business and social culture of the United States as to make it of limited relevance in the formation of appropriate strategies for New Zealand corporations.

Propositions and research questions developed from this preliminary research include the following:

* Systems thinking has been used in successful corporations for coping with internal and external complexity and continuous change (Senge, 1990).

* Systems thinking in learning organisations has superseded Taylorist and Fordist concepts of separation of work design from work implementation (Senge, 1990).

* Educational (learning) strategies can equip workers and managers to co-operate effectively in decision-making and decision-implementation (Stata, 1989).

* Companies with rapidly changing markets and technologies have a competitive advantage if they are able to develop ways of constantly learning about their internal and external environments; that is, if they become learning organisations (Senge, 1990).

No one person can be expected to have access to enough data and skills to deal successfully (as a lone individual) with the complexity of environmental flux, so team techniques of both decision-making and skills formation are necessary (Capper et al, 1994).

\section{Project design and methodology}

Based on the rationale outlined above, the ERSF research project has been designed to achieve two related objectives. The first is to identify the structural and cultural features of New Zealand enterprises that seek to achieve sustainable competitive advantage by operating as "learning organisations'. The second objective is to identify: (i) the core skill sets that managers (leaders/coaches), supervisors (team leaders) and workers (team members) require to operate effectively in the current and future business environment; (ii) how these core skills are formed and; (iii) how that skilling process is integrated into the company's strategic planning process.

The project is designed around case studies of skill formation in five New Zealand companies. Companies are being selected from a range of sectors and enterprises and cover a range of productive processes, market contexts and economic imperatives. Macro and micro-economic analysis, combined with sociological analysis, allows the project team to: (i) understand the company's skilling process in response both to the economic imperatives of the global economy, and to the external policy and industry 'drivers' that impact on the competitive positioning of businesses; and (ii) identify characteristic features of New Zealand learning organisations and to describe barriers to their successful formation.

Each case study has largely the same methodology comprising the following steps:

1.Analysis of the case study subject in relation to its macroeconomic, policy and industry context.

2.Analysis of organisational structure, process and culture, including analysis of the work-site in relation to its company structure, where relevant.

3.Analysis of selected aspects of the plant's business operating systems, work organisation, job design and management, and human resource systems.

4. Analysis of the strategy and processes by which: i) skills are defined; ii) skill needs identified and negotiated; and iii) skill formation is pursued.

The project focuses on organisational features as well as the attributes and opinions of individuals, particularly on the learning which occurs when these individuals are orgainsised into functioning teams. This latter requires consideration of cognitive issues at both the individual and group levels. Thus the case study design involves both macro and micro analysis which allows us to understand the ways in which the different dimensions or levels interact, and their impact on the competitive positioning of businesses.

Steps 2 to 4 above are based on a mix of information from semi-structured interviews, a short questionnaire ${ }^{1}$, company documents and site observations. The data sources are triangulated and analysed using analytic induction techniques, a research process that is described below. Analysis of the data relies on a series of iterations with a cross-section of company personnel as explained below. This process, with its elements of participatory action research (PAR) grounded in data gathered by conventional techniques, is intended to facilitate change in the case study organisations themselves in a methodological setting which is consistent with the concept of organisational learning.

\section{Criteria for selection of case studies}

Five private sector companies are being selected from the following list of criteria:

* Companies in sectors that currently play, or are likely to play, a significant role in New Zealand.

* Companies that have evolved out of New Zealand 
conditions, management style and culture.

* Organisations that:

- reflect a range of sectors, occupations, market contexts and economic imperatives

- have developed, or have the potential to develop, export markets

- cover a range of management, service and product development functions and a range of production processes

- are undergoing major transitions (associated with significant expansion in sales, changes in market structure and customer service functions, new production or processing systems and technologies including TQM and JT and workplace reform restructuring);

- have transformed their organisational structure into one that is team-based, and

- are explicit in their commitment to skilling staff.

\section{Project Structure}

In order to fill the identified gaps in research on skill formation, the project has been structured to include a core multi-disciplinary project team and a project advisory team that crosses sectoral boundaries. The project team of five has expertise in:

*Economic restructuring,technological change and working life in New Zealand enterprises.

* Educational research in New Zealand and internationally, particularly in the secondary school sector.

* Business experience, particularly in corporate and human resource strategy.

* Macro-economic and policy analysis.

* Quantitative and qualitative methodologies, particularly in the context of case study research.

* Working collaboratively in team research.

The establishment of a multi-sectoral Project Advisory Team (PAT) ensures that research outputs are relevant to business, unions, education providers and policy analysts. Members of the PAT team themselves are also encouraged to become engaged in the research process, thereby adding a meta-level of PAR in which people who are influential in the wider policy field do not just receive the results of the work of researchers, but participate in the discourse of the research process and contribute to the creation of meaning and theory which is intended to inform the work that they themselves do.

Membership of the team includes:

* Senior managers of New Zealand companies and govemment agencies.
* Specialists in EEO issues.

* Senior policy advisers from the Department of Labour, NZ Qualifications Authority and the New Zealand Careers Service.

* Senior officials from the Employers' Federation and the NZ Council of Trade Unions.

* Education and labour market specialists.

\section{* The Manager of the Workplace New Zealand organisa- tion.}

The PAT team meets twice yearly to provide input on research work in progress and annually, for a one day workshop, where research papers and findings are reviewed. A national seminar is planned for the final year.

Each of the five case studies is being led by a case study leader from the project team who has responsibility for managing all the research components of that site. The first case study at the Watties Frozen Foods Hornby plant has been completed and the report is being finalised.

\section{Why choose a case study approach?}

Case studies can be exploratory, descriptive or explanatory (Yin, 1989). In this project, as is usual in many case studies, considerable overlap exists between these strategies. Specifically, the case study appraoch will allow the researchers to:

1. Develop theory grounded in the case study data (Glaser and Strauss, 1967).

2. Ilustrate the utility of a theoretical framework and a set of concepts through the case studies.

3. Describe actual cases of workplace restructuring and skill formation within the context of the global economy.

4. Test hypotheses and generalise results back to theory. (This point is critically examined in the following section where issues of validity and rigour are examined.)

The case study approach has been selected because: (i) benchmarks and models of appropriate skilling strategies, rather than descriptions of broad populations, are sought; (ii) specific, and researchable, hypotheses about the corporate features of a New Zealand 'learning organisation' are not yet readily available; and (iii) research on the concept of skill formation is still at the exploratory stage.

Yin (1989) has suggested that a case study may be preferable as a research strategy when 'how' and 'why' questions are being posed, when researchers lack control over events studied, when the phenomena studied are not easily distinguishable from the context in which they occur, and, 
when the phenomena are recent or rapidly changing to make historical and archival methods inappropriate. As a research endeavour, 'the case study contributes uniquely to our knowledge of individual, organizational, social and political phenomena'. The distinctive need for case studies arises out of the desire to understand the complex mix of these phenomena within an organisational context (Yin, 1989).

The critical issue here is that the case study allows an investigation to retain the holistic and meaningful characteristics of real-life events. Hence, while case study research is not seen as yielding representative findings, there is a corresponding strength in that complex processes can be described and understood directly (Curtain, Gough and Rimmer, 1991).

Based on research experience to this point, the ERSF Project is also seeking to synthesise the conventional use of case studies with a process of participatory action research (PAR) within each case study site. As well as using the case studies to illuminate the wider patterns of organisational change and associated skills formation, the process of the research itself can be developed as a tool which might be profitably applied by any organisation seeking to clarify and develop its own skills needs and learning environment.

Thus, the conventional research procedures of data gathering and analysis are given meaning through an iterative dialogue between the researchers and the subjects, to which the researchers bring prior theory, the tools of data collection and analysis, and the skills of grounded theory building, whilst the subjects bring the insights of their practical day to day experience of the environment in which the data is being gathered. Together, researchers and subjects create a broader and deeper understanding of what is being studied that enriches the theoretical models of the researchers and the quality of the policies and management practices of the subjects. Both are described and disseminated as outputs of the project.

In this way the project attempts to bring together the two different scientific traditions of logical positivism - in which the detached scientific observer attempts to find out 'objective' truths, and that of emancipated meaning construction - in which the researcher and research subject discuss the data together in order to find out what it means.

In our study we do not reject techniques of 'normal science', but we note that modern conceptions of complexity in the biological and physical sciences compels us to the view that, as Levin (1994) puts it:

Theory, understood as meaning constructed within the scientific community, cannot be separated from the social world in which it is developed.

\section{Validity issues in the ERSF research design}

\section{Analytic Induction and Triangulation}

Some researchers question whether any valid conclusions can be drawn from case studies. For example, Fothergill and Gudgin (1985) argue that case studies should normally be avoided because it is difficult to know the extent to which the cases are typical, and the variability between cases often obscures trends that are clear when dealing with aggregate figures.

Others argue that case studies only need to be typical of wider experiences if logical inferences rather than statistical inferences are to be made. This point needs to be emphasised since researchers frequently confuse statistical generalisation (drawing inferences about a population from a sample) with logical or analytical generalisation

Table 1. Theory, people and practice

\begin{tabular}{l|l|l|l}
\hline Theory & Theory & People & Practice \\
\hline People & - & $\begin{array}{l}\text { Theory is } \\
\text { constructed based on } \\
\text { "facts" derived from } \\
\text { the social system and } \\
\text { is the task for scientists. }\end{array}$ & $\begin{array}{l}\text { Theory guides } \\
\text { practice; theory } \\
\text { first, then practice }\end{array}$ \\
\hline Practice & $\begin{array}{l}\text { People participate in } \\
\text { creating new knowledge. }\end{array}$ & - & $\begin{array}{l}\text { People act on logic and } \\
\text { models developed by others } \\
\text { developed under different } \\
\text { social and material contexts. }\end{array}$ \\
\hline & $\begin{array}{l}\text { Theory is developed } \\
\text { through solving practical } \\
\text { problems. }\end{array}$ & $\begin{array}{l}\text { Microemancipation } \\
\text { is an integral part } \\
\text { of the meaning } \\
\text { construction process }\end{array}$ & - \\
\hline
\end{tabular}


(drawing inferences about a theory or set of propositions from the case study data). Yin (1989) expresses the point well when he writes that case studies:

are generalisable to theoretical propositions and not to populations or universes. In this sense, the case study ... does not represent a 'sample', and the investigator's goal is to expand and generalize theories (analytic generalization) and not to enumerate frequencies (statistical generalization) (Yin, 1989).

For this reason, case study designs do not have the familiar probability measures of sampling error which have traditionally been seen as appropriate when there are questions as to how similar the studied sample is to the entire universe or population from which it has been drawn. Instead, a research strategy built round the techniques of analytic induction and triangulation are used to establish validity (Hill, 1984).

Like the physical and biological sciences, the social sciences have tended to emphasise deductive, hypothesistesting methods of inquiry rather than inductive methods concerned with the generation of theory (Glaser and Strauss, 1967; Taylor et al, 1990). Deductive reasoning is the logical process of deducing particular statements from general principles. Conversely, induction entails reasoning from particular observations to develop general principles. The research strategy proposed for the ERSF project uses both processes of reasoning to establish valid research findings. In practice, this involves moving back and forth from principles to specific cases and from cases to specific principles, modifying the principles to take account of cases that do not 'fit' or support prior principles (Taylor et al, 1990).

The other central concept in the validation procedure is the notion of 'triangulation' (Denzin, 1970). This technique entails using multiple sources of information, methods, theories and observers to generate a variety of data about the social phenomena under investigation. (This technique is described more fully below). The triangulation technique used in conjunction with the logical process of analytic induction provides the researcher with a systematic and reliable validation procedure.

Crucial to an understanding of analytic induction as a means of establishing valid research findings is the need to separate numbers (or quantified variables) from the notion of validity (truth). As Taylor et al. (1990) point out: "It is not the numbers that make data valid under the analytic induction process, but rather the logical integration of data from different sources and different methods of analysis into a single, consistent interpretation" (Taylor et al, 1990).

It is generally assumed that the findings from the analytical process of 'grounded theory generation' can, as the name suggests, only be generalised back to theory. In other words, traditionally no claim is made in case study design (even when multiple and iterative case studies are used) that information about other cases not yet studied may now be inferred. Instead, what is claimed is that patterns and relationships within the cases studied have been examined in enough detail to allow the creation of useful hypotheses. It is then necessary to test such hypotheses through focused quantitative studies in which random samples may be drawn and likelihoods that sample descriptions represent the entire population may be calculated.

However recent developments in the field of chaos theory, especially those parts associated with fractals (McGuinness, 1992), suggest that patterns can be identified from single case studies which are internally valid for that case study and, if similar patterns are found in other case studies, are grounds for the postulation of what Senge (1990) calls 'archetypal systems'. Such descriptions do not claim that the same archetype will be found in all organisations, but that similar systemic patterns are likely to emerge in very different environments given similar sets of conditions. Such analysis is not rigidly predictive, but describes probabilities and provides an analytical framework through which sense can be made of future studies.

Nevertheless, techniques are still needed in case studies to provide internal rigour and internal validations through various forms of triangulation and analytic induction. These techniques include:

* Team data gathering, analysis and interpretation.

* Data-gathering from multiple sources within each case study.

* Submission of reports to a cross-section of informants for their review and comments.

* Comparisons of case studies with other case studies carried out with similar objectives and methodology.

\section{Team techniques to increase rigour}

When different researchers observe, interview, and review documents to gain data about the same corporation, the subjectivities and blind spots of any one researcher become less likely to distort descriptions and interpretations. A symmetry between the object of study, learning within teams in an organisational context, and the methods of study has also been introduced through the use of research team techniques. When the researchers themselves form a work team, through participant-observer techniques they are likely to experience both the benefits of creating a group large enough to provide a needed diversity and depth of skills and the various psychological and logistical features of team work. This, in turn, can be expected to enhance their ability to identify and analyse similar features which may occur in the workplace teams being studied. Finally, when the subjects themselves become engaged in the researchers' discourse, as partners in the process, the richness of the dialectic is greatly enhanced. 
Triangulation of multiple data sources within the case study is also a rigour-enhancing research technique. Data is gathered in a variety of ways. These include document review, semi-structured scoping interviews, structured interviews, survey 'opinionnaires' (which are themselves based on multiple methods) and personal observation, sometimes aided by observation protocols. The data is also obtained in a 'multi-layered' way - that is, by triangulating the various types of data drawn "horizontally' from a variety of different departments or functions across the organisation, and 'vertically' from the top to the bottom of existing hierarchies. Consistent patterns among data derived from such widely divergent sources and types of organisational structures increases the confidence of researcher and research report reader that relevant and accurate descriptions and explanations are being made.

Contradictions among data from different sources may also trigger useful research questions in the researchers' minds. When consistent multiple triangulation patterns are identified, for example, this can suggest the existence of significantly different perceptions and understandings in different parts of the organisation. Contradictory data may also stimulate further research into the patterns of circumstances under which the contradictory indications occur, and lead to important new insights as researchers grapple with anomalies and surprises. It is therefore a basic advantage of the case study method that a richness and complexity of information, or what Geerz (1973) refers to as 'thick data', can be utilised. There is a corresponding weakness in survey research designs. When the only information readily available is that the respondent chose a particular response to a questionnaire item, the researchers have very little information as to why that response was chosen by the respondent. In contrast, case study methodology may provide adequate background data for fruitful and grounded speculation as to the circumstances under which various informants may provide contradictory points of view.

\section{Informant review as a technique for increasing rigour}

Informants whose behaviour is being studied have much greater background knowledge of the embedded details of their workplace than research team members can hope to achieve in the short periods of time available during the case study. Informants can function in a way which provides a cross-check on data interpretation. That is, they can question information or interpretation presented by research team members. This does not imply that an informant's responses to researchers' reports must be accepted at face value. However the informant may also provide additional pertinent information and altemative interpretations which enrich and perhaps even revise the interpretations to be included in the final report. If discussions with an informant reveal an on-going difference of interpretation, it may be useful to consider the inclusion of a statement of the informant's point of view .
Sometimes there is disagreement as to the data itself (a factual question). In this instance, the appropriate action is a reinvestigation of the facts. Good internal research team procedures would, in such a case, call for the reinvestigation to be performed by a different team member. At any rate, the prior knowledge that informants will be asked to review and comment upon data gathered is a factor which encourages care in its gathering. It also encourages the use of clarity and appropriate humility in data interpretation. It sometimes happens that informants disagree with other informants who review research reports. This fact should be noted and may be important enough to justify additional data-gathering and dataanalysis on the point at issue.

Finally such dialogues with informants are a crucial strut in the bridge between theory and action. As Whyte (1994) writes "... the ultimate test of a good theory is what you can do with it" (Whyte, 1994). In the social sciences that test resides in the capacity of the theory to positively inform practical actions.

\section{Multiple and Iterative Case Studies}

When similar methods are used in case studies of several different enterprises, the benefits of triangulating multiple data sources may be further extended. Similarities noted among enterprises in differing industries and with differing market niches suggest the possibility that findings of wide generalisability may be achievable. Conversely, when data from one corporate case study is in sharp contrast with data from another, it would be appropriate to search for an explanation of the variations that have been noted.

\section{Conclusion}

In conventional terms, the present research project can contribute definitions and descriptions from five coordinated case studies. Hypotheses can be generated which may guide future research in the forms of both additional case studies and quantitative studies using experimental, archival or broad survey designs. However, we are developing a different approach, consistent with that called for by Daft and Lewin (1993):

We are proposing a role for organisational scholars that is primarily one of developing new variables and theories to describe new phenomena, not to test hypotheses. If done well, the emerging knowledge will advance both organisational theory and the practice of management.

Case study research in which the researcher becomes engaged with the subject organisation allows the researcher to work 'from the inside', gives an incentive to respondents to reveal what is going on as part of their search for solutions to workplace problems, and permits the testing of new methods for helping people deal with real issues. 
The complex patterns which the researcher describes in analysing the rich data which is gathered can be generalised against known systemic archetypes or postulated as hypotheses of new archetypes. This makes the integration of 'normal science', action research and ethnographic research into a rewarding synthesis - a new research paradigm (Senge, 1993). Thus while 'normal' science places case studies in a linear process leading towards some knowable 'truth', an integrated approach leads to an iterative process which constantly redefines issues in a search for deeper levels of understanding as earlier insights are applied.

\section{Future research}

The project described here is the second one in a proposed three project sequence in which it is hoped that iterative processes both within and betwene projects will add to the depth of the insights gained. The first, and completed project, 'Reform at Work' is described here. The second project described here is at its mid point. The authors have a proposal currently under consideration entitled Learning and Enterprise in Teams and Networks.' The sequence moves from a consideration of workplace systems in the first, through to a focus on a skills needs in reformed settings in the second, to a close focus on how work team mebmers function cognitively.

\section{References}

Barnett, M. 1994 Why business must not fail to lead Dominion 27 January.

Capper, $\mathbf{P}$ with Bullard, T., Hawes, $K_{\text {., Hill, R. and }}$ Richardson, E., 1994 Organisational Learning: Current Theory and Practice in the USA, New Zealand Institute for Social Research and Development, Christchurch.

Curtain, R., Gough, R. and Rimmer, M. 1991 Award restructuring and workplace reform: An appraisal of progress based upon 33 case studies Report to the Department of Industrial Relations, Victoria University, Wellington.

Daft, R. and Lewin, A. 1993 Where are the theories for the 'new' organisational forms? Organisation Science 4(4): i-vi.

Davidson, C., Hill, R. and Perry, M.(forthcoming)Reform at Work: New Zealand workplaces in the new industrial order Longman Paul, Auckland.

de Gues, A. 1988 Planning as learning Harvard Business Review March/April 66(2).

Denzin, N. 1970 The research act; a theoretical introduction to sociological methods Aldine Pub. Co., Chicago.
Emery, M. 1993 Participative design for participative democracy Centre for Continuing Education, Australian National University, Canberra.

Ford, B. 1991 Integrating technology, work organisation and skill formation: Lessons from manufacturing for ports In M. Costa and M. Easson (eds) Australian Industry: What policy? Pluto Press, Leichardt, New South Wales.

Fothergill, S. \& Gudgin, G. 1985 Ideology and methods in industrial location research. In D. Massey \& $R$. Meegan (eds) Politics and method: contrasting studies in industrial geography Methuen, London, 27-50.

Garvin, D. 1993 Building a learning organisation Harvard Business Review July/August 71(4):78-91.

Geertz, C. 1973 The interpretation of cultures Basic Books, New York.

Glaser, B and Strauss, A. 1967 The discovery of grounded theory: strategies for qualitative research Aldine, Chicago.

Gordon, L. and Snook, I. 1992 Education, 'Skills' and technological change: the politics of the 'new economy', New Zealand Journal of Industrial Relations 17(1): 85-94.

Hill, R. 1984, Establishing validity in the social sciences: an empirical illustration. New Zealand Science Review 40(4).

Levin, M. 1994 Action research and critical systems thinking: two icons carved out of the same log? Systems Practice 7(1): 25-41.

McGuiness, M. 1992 Chaos - a walk through the garden New Zealand Science Review 49(3): 75-78.

Senge, P. 1990 The fifth discipline: the art \& practice of the learning organization Century Business, Great Britain.

Senge, P. 1993 Transferring the practice of management Human Resource Development Quarterly Spring 4(1): 5-32.

Smith, M. 1994 Human capital hits a skills wall Dominion 26 January.

Snook, I. 1994 Skills crisis myth persists Evening Post 28 February.

Stata, R. 1989 Organizational learning - the key to management innovation Sloan Management Review Spring 30(3): 63-82. 
Taylor, C., Bryan, C. and Goodrich, C. 1990 Social Assessment: theory, process \& techniques Centre for Resource Management, Lincoln University, Lincoln.

Whyte, W.F. 1994 "Encounters with participatory action research," Discussion paper prepared by William Foote Whyte for private seminar at Whyte's home, Ithaca, New York, 27 October 1994, attended by authors.

Yin, R. 1988 Case study research: design and methods Sage Publications, Newbury Park.

\section{Notes}

1 The questionnaire is more accurately described as an opinionnaire because it captures the opinions of its respondents (pers. comm. Ward Weldon).

\section{Author}

Tony Bullard, Phillip Capper, Kathryn Hawes, Roberta Hill, Evelyn Richardson and Ward Weldon are members of the ERSF project team from the NZ Institute for Social Research and Development. The demise of the Institute has seen the transfer of the project to the management of Lincoln University, who have sub-contracted it back to the authors (with the exception that Evelyn Richardson has been replaced by Dr. Charles Tustin of Otago University). The authors now trade as the Centre for Research on Work, Education and Business, Ltd. (WEB Research), PO Box 238, Lincoln University, Canterbury, phone 03-325-3891, fax 03-325-7829. E-mail of project leader hillı@lincoln.ac.nz. 